ROCZNIKI HUMANISTYCZNE

Tom LXIX, zeszyt 2 - 2021

DOI: https://doi.org/10.18290/rh21692-7

\title{
AVITAL HECHT
}

\section{PERÓN, EVITA Y LOS DERECHOS POLÍTICOS DE LA MUJER ARGENTINA}

\section{INTRODUCCIÓN}

La obtención de derechos políticos de la mujer argentina está íntimamente relacionada co las figuras de Juan Domingo Perón y Eva Perón y se concentra en el primer período presidencial de Perón (1946-1952). El papel que desarrollo Evita en la inclusión de la mujer argentina en la vida social y política de Argentina sin apelar al feminismo o a cierta exigencia de igualdad, sino determinando el papel de la mujer en base al modelo de roles que expusieron Perón y Evita en su liderazgo conjunto. Es así como fue creado el Partido Peronista Femenino, con sus filiales separatistas y con características propias de mujeres que son madres, amas de casa y esposas. El derecho de sufragio femenino no nació del pueblo sino que fue un acto con objeto de maximizar la fuerza política de Perón y Evita en una coyuntura política favorable con vistas a la reelección de Perón en 1951.

\section{EL LIDERAZGO DE PERÓN}

Juan Domingo Perón fue elegido presidente de la República Argentina por primera vez, en el mes de febrero de 1946. En el año 1951 Perón completó su primer término presidencial y fue reelegido inmediatamente a su segundo período presidencial - el cual no pudo concluir debido al golpe militar que lo

AvitAl HeCHT - Ph.D (History), Head of "Shoa Memorial Center", Gordon Academic College of Education, Haifa, Israel; e-mail: hechtavital@gordon.ac.il; ORCID: https://orcid.org/0000-0003-3771-0711. 
derrocó en 1955. Por primera vez el presidente argentino había sido reelegido consecutivamente, debido a que la Constitución Argentina no lo permitió hasta ese entonces ${ }^{1}$. Perón fue miembro del grupo militar que provocó el Golpe de Estado en 1943, golpe que estableció un gobierno militar durante los años 1943-1946 y así mismo fue parte de ese gobierno y se desempeño en los cargos de vicepresidente, Secretario de defensa y Secretario de bienestar social. La secretaría de Bienestar Social fue la que le facilitó el contacto directo con los gremios obreros, la interacción con sus dirigentes y la realización e implementación de reformas significativas- las cuales beneficiaron a los miembros de las clases sociales bajas. Durante dicho período Perón promovió y legisló una extensa cantidad de leyes y actos que otorgaron derechos a los trabajadores, mejoraron sus condiciones de trabajo y sus salarios.

Fue así que cuando en 1946 Perón fue elegido presidente, representaba de facto, dos sectores: las fuerzas armadas y el movimiento obrero. Este último veía en Perón su delegado en el gobierno, mientras que los dirigentes de las fuerzas armadas se referían al gobierno de Perón como una prolongación del gobierno militar precedente. La figura de su esposa Evita fue crucial en la elección presidencial, debido al las excelentes y cercanas relaciones que cultivó con el movimiento obrero durante el gobierno militar: es así que Evita se transformó en líder gremial de facto. Al mismo tiempo, Evita se había transformado en el hueso de discordia entre Perón, las Fuerzas Armadas y la Iglesia Católica, quienes se oponían firmemente - durante toda la cadencia presidencial, a la involucración de Evita en los aspectos de la vida política y pública del país. Dicha discordia se basaba en el pasado sombrío de Evita ${ }^{2}$. La expresión extrema de dicha resistencia tuvo lugar en el año1951, cuando Evita se vio forzada a renunciar a su postulación a la candidatura de Vicepresidente junto a Perón, en vistas a la segunda presidencia del lider. A pesar de la muerte de Evita ${ }^{3}$, antes del comienzo del segundo término presidencial de Perón, la influencia de la figura femenina, el carisma y el liderazgo que la caracterizaban, quedó impregnada en el movimiento obrero y en el Partido Peronista durante los treinta años siguientes y siguieron acompañando a Perón en su trayectoria de liderazgo hasta el tercer gobierno en 1973.

A pesar de haberse iniciado Perón en un ambiente militar, su poder personal se basó en la integración entre su rango militar, su carisma personal

\footnotetext{
${ }^{1}$ Reforma de la Constitución Argentina 1949, González Arzac, A., "La Constitución Justicialista de 1949", Todo es Historia 41 (1971).

${ }^{2}$ Debido a sus antecentes familiares y su dudoso pasado profesional como actriz.

${ }^{3}$ Evita murió de cáncer antes de las Elecciones Nacionales el 11/11/1951.
} 
y el imponente pacto estratégico con el movimiento obrero. Quizás sin proponerselo, consiguió revivir el personaje histórico del Caudillo ${ }^{4}$, a pesar que en sus escritos Perón condena a la figura del caudillo por su transitoriedad, en tanto que el verdadero líder se destaca por su influencia a largo lapso y a diferencia del caudillo que se caracteriza por el desorden, el verdadero líder se apoya en la organización para lograr sus objetivos ${ }^{5}$. Perón creía que el líder que no logra dejar su marca en su pueblo, es Caudillo y no Líder. Ser líder es un arte, ser caudillo es una profesión... ${ }^{6}$

\section{PERÓN Y EL GÉNERO FEMENINO}

A pesar que es difícil encontrar en las obras de Perón referencias ideológicas al status de la mujer en la sociedad argentina, siendo Secretario de Bienestar Social en el gobierno militar de 1943, comenzó Perón a ocuparse de dichos temas. Las referencias de Perón a la mujer y su lugar en la sociedad no son políticas ni ideológicas; en general estan relacionadas con comentarios machistas en los que denomina a los seres masculinos bajo el apelativo "Hombre"7 Del mismo modo - en el ámbito politico, Perón hace referencia al hombre como miembro del Partido Peronista.

A pesar de ello, Perón fue quien promovió el derecho de sufragio de las mujeres argentinas y logró concederlo, sin necesidad de confrontaciones o discusiones ideológicas. Su pragmatismo y percepción de que el voto femenino arrastraría beneficio electoral inmediato, promovió Perón un significativo y radical cambio. A pesar que durante medio siglo mujeres socialistas exigieron constantemente que se les adjudique el derecho de voto femenino, no es posible relacionarla histórica o socialmente con la decision de Perón. El 23 de Septiembre de 1947 el Congreso Argentino aprobó la ley de sufragio femenino universal.

Ya en 1944, siendo Secretario de Trabajo y Bienestar Social en el marco del gobierno militar, creó Perón la "dirección nacional de mujeres dependientes",

\footnotetext{
${ }^{4}$ Caudillo es una figura política, dirigente y líder que se conformó a principios del siglo XIX, imediatamente después del proceso de independencia de los paes sudamericanos. Ver I. Rachum, "Latin América Caudillos: the rise, advance and possible demise of a political tradition", en Bar Ilan Studies in History V (Ramat Gan, 2007), 117-139.

5 J. Domingo Perón, Conducción Política (Buenos Aires: Freeland, 1974), 47.

${ }^{6}$ J. Domindo Perón, Doctrina Peronista (Buenos Aires: Macacha Güemes, 1973), 147.

${ }^{7}$ J. Domingo Perón, Los Libros del Exilio 1955-1973 (Buenos Aires: Corregidor, 1996), 27.
} 
para poder otorgar tratamiento adecuado y responder a las necesidades económicas de aquellas amas de casa que dependen absolutamentes de sus maridos debido al sistema tradicional argentino, el cual creó una clara division familiar. Asimismo, esa entidad se haría cargo de las mujeres solteras o casadas de bajos recursos económicos familiares, que salían a trabajar fuera de sus hogares por necesidad económica. El trabajo femenino era interpretado como necesidad básica de aquellas débiles mujeres y no como expresión de independencia económica. Esta nueva entidad se transformó en uno de los brazos ejecutivos de la Secretaría de Trabajo al frente de Perón con efecto de promover y preservar los derechos femeninos, viéndolos como parte integral del quehacer económico nacional, entre ellos la licencia por maternidad y el derecho femenino a la propiedad $^{8}$. Este precedente tanto ideológico como ejecutivo, constituyó el primer paso de Perón dentro del mundo de derechos femeninos y otorgó a la mujer argentina un nuevo status social y familiar.

En el mes de julio de 1945, el Secretario de Trabajo Juan Domingo Perón, establece la creación de una comisión especial con el objeto de promover el derecho de sufragio femenino. Rosa Bazán de Cámara fue designada presidenta de la comisión (Diario La Nación 6), que determinó que la negación del derecho de sufragio al sector femenino constituía una injusticia que debe ser reparada. Si bien Perón apoyo las conclusions de la comisión, no recurrió a ningún acto práctico para implementarlas o legislación alguna. Es así que solo un año más tarde, Perón hizo declaraciones políticas junto a Evita, refiriéndose por primera vez a los derechos politicos femeninos, en ocasión en la que presentó al Congreso Nacional una propuesta de ley en la que exigía otorgar derecho de sufragio a la mujer argentina (Palermo 1-68). La ley de sufragio femenino - número 13.010 fue aceptada por el Congreso de la Nación el 23 de Octubre de 1947, y por primera vez los derechos cívicos de hombres y mujeres argentinos fueron igualados. La Ley Sáenz Peña que otorgaba derechos universales a todos los seres humanos de género masculino, se transformo en una ley sin diferencias de género ${ }^{9}$. Cabe destacar que Argentina no fue pionera en cuanto se refiere al sufragio femenino. Si bien Nueva Zelanda lleva la primacía, estableciendo el voto femenino en el año 1902, durante las dos primeras décadas del siglo XX, paises en el viejo continente introdujeron la reforma política y social que estableció el sufragio

\footnotetext{
${ }^{8}$ L. Golbert, De la sociedad de beneficencia a los derechos sociales (Buenos Aires: Ministerio de Trabajo, Empleo y Seguridad Social, 2010), 82-83.

${ }^{9}$ Ley Saénz Peña, sancionada por el Congreso Nacional Argentino el 10/2/1912 estableció voto obligatorio y secreto para todo ciudadano masculino mayor de 18 años.
} 
femenino, basado generalmente en las exigencias de movimientos sufragistas femeninos ${ }^{10}$. El nuevo continente adopto leyes de sufragio femenino a partir de la tercera década del siglo XX, siendo Estados Unidos quien ya en 1920 otorgó el derecho de sufragio a las ciudadanas de género femenino. A pesar que Uruguay y Ecuador adoptaron leyes de sufragio femenino en 1927 y 1929 , su implementación fue en los años 30 del siglo.

Quizás el punto de interés en la adopción del voto femenino promovida por Perón y Evita en Argentina, reside en el hecho que dicha iniciativa no fue fruto de una lucha social o exigencia política de grupos feministas, sino que fue un gesto de generosidad políca del líder basado en especulaciones electorales.

\section{EVA PERÓN Y LOS DERECHOS CÍVICOS FEMENINOS}

[...] La Nación necesita de una madre para sus hijos, pero también necesita una ciudadana $[\ldots]$ La Descamisada $[\ldots]^{11}$.

En esta declaración Evita se refiere a la importancia que existe en la igualdad de los derechos políticos de la mujer peronista, para que ésta sea partícipe de la vida política del país y de los acontecimientos que llevaron a la representación del pueblo a través de Perón y su gobierno. El apodo "descamisado" se refería a los simples trabajadores que apoyaban a Perón y que durante las manifestaciones en favor de la liberación de Perón de su prisión militar en 1945, se quitaron sus camisas debido al calor que los agobiaba y siguieron manifestando en cueros. El periodismo liberal identificado con la clase media y con la Unión Cívica Radical que se oponía a Perón - fundamentalmente concentrado en los diarios La Nación y La Prensa ${ }^{12}$, los apodo "descamisados", despreciativamente, pero los manifestantes y partidarios de Perón adoptaron dicho apodo a través de toda la trayectoria gubernamental hasta su muerte. En diferentes ocasiones Perón acostumbraba a sacarse la chaqueta a manera de expresar su identificación con los "Descamisados"13.

\footnotetext{
${ }^{10}$ Finlandia en 1906, Noruega en 1913, URSS en 1917, Alemania e Inglaterra 1918.

${ }^{11}$ Discurso de Evita en Diario La Nación, 19/3/1947.

${ }^{12}$ Diario La Nación 8/12/1945, 1; Diario La Prensa 8/12/1945, 3.

${ }^{13}$ S. PALERMO, "Quiera el hombre votar, quiera la mujer votar: género y ciudadanía política en Argentina (1912-1947)", en C. Barry (comp.), El Sufragio Femenino en América Latina (Buenos Aires: Universidad Nacional de Tres de Febrero, 2006), 1-68.
} 
Dichas declaraciones de Evita constituyeron el foco de la campaña política a favor de la ley de sufragio femenino. En un discurso radiofónico que fue transmitido el 12 de febrero de 1947 explicó a las mujeres cuales eran las ventajas de la aplicación del voto femenino, tanto en el aspecto de los derechos de la mujer como de la esposa y ama de casa que ama a su familia:

[...] con el voto no solo defendemos el jornal mejor de tu marido y el acceso al techo digno y al pan común sino además defendemos el derecho de opinar en la mesa del hogar que hicimos laboriosamente $[\ldots]^{14}$.

La concepción ideológica de Evita con respecto a los derechos femeninos era muy sectorial. En sus discursos se refería siempre a las obreras o a las esposas de los obreros. A su entender, el derecho a sufragio femenino constituía una compensación por la gran carga que llevaban las mujeres sea en su puesto de obreras, madres o esposas.

El 9 de septiembre de 1947 fue sancionada la ley 13.010 que otorga derecho igualitario de sufragio a las mujeres argentinas, igualando así los derechos cívicos masculinos y femeninos. A pesar de que entre los años 1912-1947 fueron propuestas diferentes leyes de sufragio femenino, fue el primer gobierno peronista quien logró aprobar la ley. La campaña en favor del derecho de sufragio femenino se transformó en la plataforma del poder y del liderazgo de Evita, tanto dentro del partido peronista como asimismo en el marco politico. La Ley de Sufragio Femenino se exhibió como logro personal de la primera dama y del partido peronista, sin hacer referencia alguna a la lucha llevada acabo durante más de cincuenta años de lucha parlamentaria y política para lograrlo ${ }^{15}$.

En el discurso que pronunció Evita inmediatamente después de la aprobación de la ley se dijo:

[...] Ha llegado la hora de la mujer que comparte una causa pública y ha muerto la hora de la mujer como valor inerte y numérico dentro de la sociedad. Ha llegado la hora de la mujer que piensa, juzga, rechaza o acepta, y ha muerto la hora de la mujer que asiste, atada e impotente, a la caprichosa elaboración política de los destinos de su país, que es, en definitiva, el destino de su hogar. Ha llegado la hora de la mujer argentina, íntegramente mujer en el goce paralelo de deberes y derechos comunes a todo ser humano que trabaja, $\mathrm{y}$ ha muerto la hora de la mujer compañera ocasional y colaboradora ínfima. Ha llegado, en síntesis, la hora de la mujer argentina redimida

\footnotetext{
${ }^{14}$ E. Perón, Eva Perón habla a las mujeres (Buenos Aires: Editorial de la Reconstrucción, 1975), 48.

${ }^{15}$ M. NAVARRo, Evita (Buenos Aires: Planeta, 1994), 195.
} 
del tutelaje social, y ha muerto la hora de la mujer relegada a la más precaria tangencia con el verdadero mundo dinámico de la vida moderna $[\ldots]^{16}$.

A pesar de ello, Evita se mostro en actitud muy modesta al respecto. En declaraciones públicas que hizo repitió a menudo:

[...] que me faltaba hacer, una mujer modesta de pueblo, en lugar que otras mujeres fracasaron....? Lo primero que debí hacer en el marco de nuestro movimiento femenino de mi patria fue solucionar el antiguo problema de los derechos civiles de las mujeres $[\ldots]^{17}$.

Por primera vez en la historia argentina, el gobierno nacional se sumó a la exigencia de igualdad de derechos cívicos femeninos y actuó para conseguirla. Evita, sin ser parte formal del gobierno se sumó a los esfuerzos y convenció a su marido Perón para que apoyara los derechos femeninos. Cabe destacar que dicho apoyo durante el período que precedió a las elecciones generales, gozaba de valor doble:

a. Incremento de la cantidad de votos a favor de Perón - quien sería identificado como el responsible del derecho de voto femenino.

b. Las mujeres - estando agradecidas por los esfuerzos de Perón y en reconocimiento a su nueva situación civil, podrían influir sobre los miembros de sus familias y convencerlos de votar en favor de Perón.

De todos modos, debemos recordar que en los escritos ideológicos de Perón no encontramos referencia alguna al sufragio femenino o igualdad de derechos a la mujer, lo que induce a la conclusión que fue este un paso político y pragmático de Perón y Evita con objetivos electorales y sin ninguna base ideológica anterior.

Una vez asegurado el derecho de sufragio femenino en 1947, Evita pudo dedicarse a fortalecer su status político. Fue así que se dirigió en un discurso público a las mujeres argentinas y les explicó que no basta con el derecho de sufragio, sino que ellas deben saber como votar en forma correcta ${ }^{18}$. Poco a poco se abrieron centros de actividad civil en diferentes barrios y suburbios bajo el nombre de Evita. Las apariencias daban de creer que dichos centros se basaban en trabajo voluntario de sus activistas sin ningún rastro de identidad política. La realidad era distinta: los centros cívicos tenían como objeto fortalecer la imagen de Evita y dar a conocer la campaña de seguridad y justicia

${ }^{16}$ Diario La Nación, 10/9/1947.

17 "Discurso de Evita", Diario La Razón 10/9/1947.

${ }^{18}$ E. Perón, Mensajes y Discursos (Buenos Aires: Fundación de Investigaciones Históricas, 1999), 168. 
social que ella encabezaba. De aquí que queda claro el eje entre el derecho de sufragio femenino y las ambiciones políticas de Evita.

El derecho de sufragio femenino pudo ser concretado por las mujeres argentinas cuatro años después de ser sancionada la ley respectiva. Durante ese período la influencia del partido peronista se incrementó notablemente, llegando a su cumbre máxima en las elecciones generales de 1951 como consecuencia de una campaña electoral popular que tuvo como foco la exigencia de la elección de Evita como vicepresidente de Perón. Pero Evita nunca fue parte de la formula electoral junto a Perón, debido a la firme oposición de las Fuerzas Armadas y la Iglesia, que pusieron veto a la postulación de Evita ${ }^{19}$. Evita falleció de cancer, antes de las elecciones y sin formar parte de la formula electoral.

\section{EL PARTIDO PERONISTA FEMENINO - PPF}

El Partido Peronista Femenino fue constituído el 29 de Julio de 1949. Evita fue su presidenta ${ }^{20}$. Perón y Evita veían en él instrumento de fortaleza y conservación del poder político que habían consolidado en su favor y la garantía del triunfo en las elecciones que se aproximaban en 1951.

La Ley de Sufragio Femenino y el Partido Peronista Femenino consolidaban en conjunto las columnas del futuro triunfo electoral y la continuidad gubernamental de Perón. Pero ello no bastaba, debido a que la Contitución Argentina no permitía que el Presidente fuera reelegido dos cadencias consecutivas. Era necesario realizar una reforma constitucional para poder consolidar todos los esfuerzos y canalizarlos a la meta deseada: la reelección de Perón. El 11 de Marzo de 1949 finalizó con éxito el proceso de reforma constitucional que incluía varios artículos, siendo el artículo 77 motivo principal y quizás único de la reforma, al ser reemplazado de modo que a partir de esa fecha el Presidente de la Nación podría ser reelegido sin limitación de cadencias ${ }^{21}$. El resultado de las elecciones generales subsiguientes acreditó $63.9 \%$ de los votos femeninos en favor del candidato Perón.

\footnotetext{
${ }^{19}$ Ver discurso en Diario La Nación 1/9/1951 en el que Evita renunció a la candidatura a vicepresidente.

${ }^{20}$ C. BARRY, "Eva Perón y la organización política de las mujeres", en Serie Documentos de Trabajo (Buenos Aires: Universidad del Centro de Estudios Macroeconómicos de Argentina, 2011).

${ }^{21}$ C. BARry, Evita Capitana. El Partido Peronista Femenino 1949-1955 (La Plata: EDUNTREF, 2009), 12-16.
} 
Si bien el PPF fue creado bajo el ideal de igualdad de derechos civiles y la realización política de las mujeres, la realidad fue que el nuevo partido se manejaba bajo la sombra del Partido Peronista - que era masculino. La situación era paradójica, ya que por un lado aspiraban a adjudicar derechos civicos a las mujeres y por el otro conservaron la separación entre hombres y mujeres. ¿Cuáles eran las intenciones de Perón y Evita cuando crearon dicha dicotomía?

Del análisis de la actuación y la dirección del PPF obtenemos una institución gubernamental y jerárquica bajo control policial. El orígen de los fondos que solventaban salario de sus empleadas que en su mayor parte se dedicaban al reclutamiento de nuevas miembros (compañeras), era gubernamental ${ }^{22}$. Así fue constituído el poder de la presidenta del PPF - Evita, en forma piramidal. El PPF fue creado con el objeto de conseguir dos fines: transformar a Evita formalmente en figura política electoral en base a su poder personal y politico, sin tener que basarse en su status de "primera dama" y junto con ello, asegurar la reelección de Perón a través del voto femenino peronista.

Las sedes del PPF funcionaban bajo el modelo de clubes vecinales ${ }^{23}$ en los que aprendían las mujeres a leer y escribir y también algunas profesiones. Luego se incorporaron actividades de bienestar social como localización y atención a familias necesitadas ${ }^{24}$. Fue así que la adhesión de nuevas compañeras al partido se hacía en base a temas de interés femeninos, necesidades primarias o ayuda mutual ${ }^{25}$. Podemos identificar ese ánimo en el discurso de Evita el 27 de Julio de 1949, en el que pide a las miembros del PPF que no la vieran como figura política. A pesar de ser la presidente del PPF, Evita declaraba constantemente que no era su actividad política, sino apoyo dedicación al pueblo y a los necesitados. Se esforzaba por aparecer como una figura desmantelada de todo interés politico o personal que se guiaba por vocación de misión y dedicación a su pueblo ${ }^{26}$.

El pueblo argentino recibió en forma positiva la iniciativa del voto femenino y la igualdad de derechos cívicos, pero aún no estaba preparado para reconocer el liderazgo politico de una mujer. Perón y Evita lo sabían. Es por ello

\footnotetext{
${ }^{22}$ BARRY, Evita Capitana, 12-16.

${ }^{23}$ Cuaderno de Ayuda (Partido Peronista Argentino. Unidad Básica Femenina Chenaut), Caso No. 16 (1940).

${ }^{24}$ S. Bianchi, N. Sanchís, El Partido Peronista Femenino (Buenos Aires: Centro Editor de América Latina, 1988), 45.

${ }^{25}$ Perón, Mensajes y Discursos, 111.

${ }^{26}$ Disertación de L. Luna, "Populismo, nacionalismo y maternalismo: casos peronista y gaitanista", en Congreso XII de AHILA (Porto, 21-25 de Septiembre 1999), 192.
} 
que Evita decidió actuar bajo retórica de justicia social y beneficencia. Dicha retórica se destaca en el lenguaje utilizado en la adhesión de mujeres al PPF. En tanto en el partido peronista se utilizaba el término político "reclutamiento", Evita prefirió que en el PPF denominara a dicha actividad "censo" que tenía por objeto comprobar la situación de dichas mujeres, a pesar de que el acto de facto constituía la adhesion al $\mathrm{PPF}^{27}$. Las diferencias en el modo de operar entre el partido peronista y el PPF eran muy claras. Las características de la actividad masculina del partido eran políticas, mientras que en el PPF se caracterizaban como actividades comunitarias que tenían por objeto promover la "justicia social". En definitiva, Evita fue la figura femenina ideal de mayor influencia en la política de estado en América Latina, transformandose en líder populista que ayudó a Perón a acceder a un extenso apoyo popular ya en el año $1945^{28}$.

\section{LA VICEPRESIDENCIA Y EL RENUNCIAMIENTO}

La cima del éxito de Evita en su papel de líder de los trabajadores llegó en el mes de Agosto del año 1951. En vistas de las elecciones presidenciales llegó una propuesta de la Secretaría General de la Confederación General del Trabajo - CGT: Evita sería la candidata a la vicepresidencia por el partido peronista, junto a Perón. Los líderes de la CGT convocaron a todos los trabajadores a una manifestación en la Plaza de Mayo (plaza en la ciudad de Buenas Aires que está ubicada frente a la Casa de Gobierno), el día 22 de Agosto de 1951, con el fin de expresar el apoyo popular a la propuesta, decretando así una huelga general para asegurar la máxima participación de los trabajadores en la manifestación. La convocatoria tuvo éxito y participaron en la manifestación dos millones de trabajadores de todo el país ${ }^{29}$. El partido Peronista y el movimiento obrero se unieron bajo la propuesta de la candidatura de Evita a la vicepresidencia, mientras Evita se empeñaba en negar toda relación con dicha iniciativa. Joseph Page está convencido que fue la misma Evita quién concibió la idea y empujó a los dirigentes de la CGT a proponerla, y de esa forma obligar a Perón a aceptar su cantidatura, a pesar que se oponía a la idea ${ }^{30}$.

\footnotetext{
${ }^{27}$ BARRY, Evita Capitana, 24.

${ }^{28}$ A. Ciria, Perón y el Justicialismo (Buenos Aires: Siglo Veintiuno, 1971), 111-117.

29 J. PAGe, Perón (Buenos Aires: J. Vergara, 1984), 285.

${ }^{30}$ Page, Perón, 285.
} 
Así ocurrió que durante la manifestación multitudinaria, el Secretario General de la CGT - José Espejo, presentó su propuesta frente a Evita y todos los participantes ${ }^{31}$.

Tanto Perón como Evita pronunciaron discursos durante la manifestación, sin hacer mención a la propuesta de Espejo. Estando aún parados en el balcón de la Casa de Gobierno, se desenvolvió un diálogo espontáneo entre el pueblo presente en la plaza - que exigía respuesta inmediata a la propuesta y Evita ${ }^{32}$. A pesar que Evita pidió que le otorguen cuatro días para responder, los manifestantes no accedieron a su solicitud. Acordaron que Evita les respondería en el término de dos horas, en un discurso radiofónico, pero Evita no cumplió su promesa. Dicho silencio fue interpretado por la dirigencia obrera como respuesta afirmativa a la propuesta, lo que llevó a la dirigencia a realizar declaraciones públicas que confirmaban la candidatura de Evita a la vicepresidencia, junto a Perón. A consecuencia de las declaraciones, tambien la dirigencia del partido peronista se acopló a la iniciativa, aprobando el 27 de Agosto de 1949 la formula electoral Perón-Perón. Finalmente, Evita en un discurso radiofónico el día 31 de Agosto agradeció a todo el pueblo su apoyo a la candidatura, negandose a aceptarla ${ }^{33}$. Los dirigentes gremiales y peronistas aceptaron la negación de Evita sin oponerse y decidieron conmemorar el hecho bajo el nombre "Día del Renunciamiento" el cual se transformó en fecha histórica de recordación durante todos los años del gobierno peronista.

Los motivos por los cuales decidió Evita no aceptar la propuesta de la candidatura a la vicepresidencia fueron dos:

a. La avanzada enfermedad de cancer de la que padecía y se había mantenido en secreto.

b. La resistencia de Perón a aceptar la iniciativa debido a las presiones de los jefes de las Fuerzas Armadas que no podan concebir una posible situación en la que la vicepresidente herede al Presidente y de ese modo pasaría a ser Comandante en Jefe del Ejército Argentino.

La muerte de Evita acarreó cierta decadencia en el PPF, pero no afectó a su figura legendaria que se transformó en símbolo de la mujer política. Evita fue envuelta en un velo de santidad, mezcla de adoración y culto politico. Edificios de instituciones públicas se crearon a su nombre, recordando su memoria, e incluso hubo un intento de santificarla en la Iglesia Católica -

\footnotetext{
${ }^{31}$ Page, Perón, 291.

${ }^{32}$ Entrevista al profesor Horacio Pereyra - asesor de J.D. Perón durante la primera presidencia (1946-1952), Buenos Aires, 19/6/1990.

${ }^{33}$ Perón, Mensajes y Discursos, 165-167 (Día del Renunciamiento 30/8/1951).
} 
intento que el Vaticano rechazó. En términos general gran parte de las referencias a Evita son de tipo maternalista, a pesar de su quehacer en el campo politico y comunitario en favor de los derechos cívicos femeninos.

La acción de Evita y el PPF vieron sus frutos cuando inmediatamente después de su muerte. Ciento nueve mujeres que Perón y Evita habían designado para ser legisladoras y senadoras en el Congreso Nacional fueron aprobadas por la Asamblea General del Partido Peronista. Todas ellas conjuntamente, declararon que serían fieles representantes de Evita en sus funciones como congresales $^{34}$. Por primera vez - en el año 1953, una mujer fue elegida como vicepresidente de la Cámara de Diputados Nacional. Delia Degliuomini de Parodi fue la primer mujer en el mundo que ocupó dicho importante puesto, habiendo sido una de las creadoras del PPF junto a Evita y quien ocuparía su puesto como presidenta del partido luego de su muerte ${ }^{35}$.

\section{CONCLUSIONES}

La iniciativa de nombrar a Evita como candidato a un cargo que hasta ese entonces era considerado absolutamente masculino, fue un acto revolucionario en la idiosincracia política y social argentina y forma parte del cambio radical que creó la sanción de la Ley de Sufragio Femenino. En un corto período podemos apreciar los cambios por los que pasó la sociedad argentina respecto a los derechos de la mujer: derecho a votar, creación de un partido político femenino y la iniciativa que una mujer sea candidata a vicepresidente. Este cambio radical en la idiosincracia política peronista se verá reflejado treinta y dos años más tarde bajo la disposición de aceptar a Isabel Perón como vicepresidente durante la tercera cadencia de Perón.

El liderazgo de Evita fue el que le permitió promover los derechos femeninos. Tanto el sufragio femenino como la legitimación social de la actividad politica de las mujeres, la posibilidad de ser elegidas para cargos politicos y la posibilidad de ver a las mujeres como parte integral del panorama politico; todos ellos fueron logros personales de Evita y no del movimiento feminista en Argentina - incluyendo el PPF. Ningún movimiento de orientación feminista consiguió promover mejoras en la condición polica de la mujer argentina y sus derechos, antes de la aparición de Evita. La acción del presidente Perón

${ }^{34}$ LUNA, "Populismo, nacionalismo y maternalismo", 195.

35 D. PARodi, "Una Mujer en el Congreso", en Colección Vidas, Ideas y Obras de los Legisladores Argentinos (Buenos Aires: Círculo de Legisladores de la Nación Argentina, 1998). 
y el liderazgo de Evita fueron los que posibilitaron logros tangibles en el status politico y social de la mujer argentina, a pesar que la ideología peronista no se había expresado en favor del feminismo o de los derechos femeninos. La integración entre las exigencias del movimiento social junto a la legislación específica fue la que preparó el terreno hacia un cambio significativo, posibilitando futuros cambios políticos como la elección de Isabel a la vicepresidencia y su futuro cargo de presidenta en los años 1973-1976.

\section{BIBLIOGRAFIA}

FUENTES

Diario La Nación, 10/9/1947.

Diario La Nación, 27/7/1945.

Diario La Prensa, 8/12/1945.

Diario La Razón, 10/9/1947.

\section{ESTUDIOS}

BARry, Carolina. "Eva Perón y la organización política de las mujeres". En Serie Documentos de Trabajo. Buenos Aires: Universidad del Centro de Estudios Macroeconómicos de Argentina, 2011.

Barry, Carolina. Evita Capitana. El Partido Peronista Femenino 1949-1955. La Plata: EDUNTREF, 2009

Bianchi, Susana, Sanchís Norma. El Partido Peronista Femenino. Buenos Aires: Centro Editor de América Latina, 1988.

Ciria, Alberto. Perón y el Justicialismo. Buenos Aires: Siglo Veintiuno, 1971.

Cuaderno de Ayuda. Partido Peronista Argentino. Unidad Básica Femenina Chenaut. Caso No. 16 (1940).

Domingo Perón, Juan. Conducción Política. Buenos Aires: Freeland, 1974.

Domingo Perón, Juan. Doctrina Peronista. Buenos Aires: Macacha Güemes, 1973.

Domingo Perón, Juan. Los Libros del Exilio 1955-1973. Buenos Aires: Corregidor, 1996.

Golbert, Laura. De la sociedad de beneficencia a los derechos sociales. Buenos Aires: Ministerio de Trabajo, Empleo y Seguridad Social, 2010.

LUNA, Lola. "Populismo, nacionalismo y maternalismo: casos peronista y gaitanista". En Congreso XII de AHILA. Porto, 21-25 de Septiembre 1999.

NAVArro, Marysa. Evita. Buenos Aires: Planeta, 1994.

Page, Joseph. Perón. Buenos Aires: J. Vergara, 1984.

PALERMO, Silvana. "Quiera el hombre votar, quiera la mujer votar: género y ciudadanía política en Argentina (1912-1947)". En C. Barry (comp.). El Sufragio Femenino en América Latina, 1-68. Buenos Aires: Universidad Nacional de Tres de Febrero, 2006.

PARODI, Delia. "Una Mujer en el Congreso". En Colección Vidas, Ideas y Obras de los Legisladores Argentinos. Buenos Aires: Círculo de Legisladores de la Nación Argentina, 1998. 
Perón, Eva. Eva Perón habla a las mujeres. Buenos Aires: Editorial de la Reconstrucción, 1975. Perón, Eva. Mensajes y Discursos. Buenos Aires: Fundación de Investigaciones Históricas, 1999.

\section{PERÓN, EVITA Y LOS DERECHOS POLÍTICOS DE LA MUJER ARGENTINA}

$$
\text { R e s u m e n }
$$

El primer gobierno de Juan Domingo Perón fué el que sentó la base de los derechos cívicos de la mujer argentina. Tanto Eva Perón como el mismo presidente supieron identificar la oportunidad y el potencial del voto femenino, con el fin de fortalecer las bases electorales del partido peronista y de sus jefes. A pesar que Evita no pudo ejercer un puesto ejecutivo en el marco presidencial, fue ella quien bajo su sombra y liderazgo, se creó el Partido Peronista Femenino, fué sancionada la Ley de Sufragio Femenino en 1947 y promovió junto con la Confederación General del Trabajo (CGT) la iniciativa de su propia postulación a la vicepresidencia. La colaboración entre Juan Perón, Evita y el movimiento obrero, transformaron la segunda mitad de los años cuarenta del siglo veinte en la cuna de la implementación de la igualdad cívica argentina, en términos de género. El derecho de voto femenino ubicó a la mujer argentina en un nuevo status desde el cual pudo influir en el ámbito pólitico y social de su país, aún fuera de su hogar y de su círculo familiar. En las elecciones de 1951, a pesar de la muerte de Evita y del anterior "Renunciamiento", Juan Perón fue reelecto con mayoría de votos femeninos. Años más tarde, en 1973, Isabel Perón - su tercera esposa, fue electa vicepresidente en vísperas de la tercera presidencia de Juan Perón - conformando la fórmula presidencial Perón-Perón y posteriormente se transformará Isabel en Presidenta de la República Argentina (1974-1976), por el Golpe de Estado que instituyó la dictadura militar.

Palabras claves: Evita; Partido Peronista Femenino; Perón; Renunciamiento; Sufragiofemenino.

\section{PERÓN, EVITA A PRAWA POLITYCZNE ARGENTYNEK}

$$
\text { Streszczenie }
$$

Pierwsza administracja prezydenta Juana Domingo Peróna doprowadziła do nadania argentyńskim kobietom praw obywatelskich. Zarówno Eva Perón, jak i prezydent byli w stanie określić możliwości i potencjał głosów kobiet służący wzmocnieniu partii peronistów. Chociaż Evita nie mogła sprawować funkcji prezydenta, kilka kwestii rozstrzygnięto pod jej wpływem i przywództwem. Co najważniejsze, partia peronistów doprowadziła do uchwalenia w 1947 r. ustawy o prawie kobiet do głosowania. Ponadto inicjatywa nominacji Evity Perón na wiceprezydenta była promowana przy wsparciu CGT. Współpraca między Peronem, Evitą i ruchem robotniczym przekształciła drugą połowę lat 40. XX w. w okres wdrażania argentyńskiej równości obywatelskiej pod względem płci. Prawo do głosowania pozwoliło Argentynkom osiągnąć nowy status, dzięki któremu mogły one wpływać na politykę i życie społeczne swojego kraju, a także na swój krąg rodzinny. W wyborach w 1951 r., pomimo śmierci Evity i jej wcześniejszego „wyrzeczenia się” kandydatury na wiceprezydenta, Juan Perón został ponownie wybrany prezydentem większością głosów kobiet. W 1973 r. Isabel Perón, trzecia żona Juana, została wybrana na wiceprezydenta tuż przed trzecią kadencją męża - kształtując prezydencką formułę Peron-Peron. Później Isabel została prezydentem Argentyny (1974-1976), jej władzę obalono w wojskowym zamachu stanu.

Słowa kluczowe: Evita; Kobieca Partia Peronistów; Perón; rezygnacja; sufrażystka. 


\section{PERÓN, EVITA AND THE POLITICAL RIGHTS OF THE ARGENTINIAN WOMEN}

\section{S u m m a ry}

Juan Domingo Perón's first administration led to the basis of the civic rights of the Argentinian women. Both Eva Perón and the President were able to identify the opportunity and the potential of the female vote, in order to strengthen the electoral basis of the Peronist party and their heads. Although Evita could not be in an executive position in the presidential setting, a few things happened under her influence and leadership. Most importantly, the female Peronist party was created and the law of women's right to vote was passed in 1947. Furthermore, the initiative of her nomination to the Vice Presidency was promoted with the support of CGT. The collaboration between Peron, Evita and the labor movement, transformed the second half of the forties of the twentieth century in the cradle of the implementation of the Argentinian civic equality, in terms of gender. Female voting rights gave Argentinian women a new status from which they could influence the politics and social life in their country, in addition to their influence on their family circle. In the 1951 elections, despite the death of Evita and her previous "renunciation" to be a Vice President candidate, Juan Perón was re-elected with a majority of female votes. Later, in 1973, Isabel Perón, Juan's third wife, was elected as a Vice President right before the third Presidency of Juan Perón shaping the presidential formula Peron-Peron. Later, Isabel will become the President of Argentina (1974-1976), until she was overthrown in a military coup.

Keywords: Evita; Female Peronist Party; Perón; Resignation; Female Suffrage. 